\title{
Performance Evaluation of Internal Combustion Engine by using MWCNT/Water based Nanofluid as a Coolant
}

\author{
M. Muruganandam ${ }^{1 \dagger}$ and P. C. Mukesh $\operatorname{Kumar}^{2}$ \\ ${ }^{1}$ Department of Mechanical Engineering, Saveetha Engineering College, Saveetha Nagar, Thandalam, Chennai \\ - 602105, Tamilnadu, India \\ ${ }^{2}$ Department of Mechanical Engineering, University College of Engineering, Dindigul-624622.Tamilnadu, India
}

†Corresponding Author Email: muthumuruga26@gmail.com

(Received May 15, 2018; accepted July 18, 2018)

\begin{abstract}
The implications of Internal Combustion (IC) Engines are complex now a day in a fast living technical field. Much work have been done on IC engines to enhance their performances with engine modification, alternate fuels, fuel supply system, combustion system and cooling systems. However every trial has its own merits and demerits. In particular, reaching the limit of conventional coolants. In this investigation, so called novel fluids MWCNT nanofluids at $0.1,0.3$, and $0.5 \%$ volume concentration are taken as IC engine coolant to study its performances and compare with the performances of water. The test is performed at five electrical loadings and by keeping flow rate of coolant $300 \mathrm{LPH}$ as constant. It is found that the mechanical efficiency is enhanced by 13 to $24 \%$, the Break thermal efficiency increases by $9-21 \%$, the TFC reduces $9-19 \%$, and the exhaust temperature of the engine decreases by $5-10 \%$ at $0.3 \%$ vol. concentration of nanofluids. The $0.3 \%$ nanofluids found to have better performance while compared with water at the same engine conditions.
\end{abstract}

Keywords: Conventional fluid; Nanofluid; Stability; Load; Performance.

\section{INTRODUCTION}

Iijima (1991) discovered the Carbon nanotubes (CNTs) in the year 1991 first. It was the process of a water cooling system which was used in the IC engine to give an increase performance by Choi (1995), Elcock (2007) and Hindwai (2009). It's an experiment in technological areas, Engine cooling, in diesel electric generator the jacket is used as water coolant. These are different applications used in this research heating and cooling of building, cooling of hardware, and cooling of welding, Nanofluids in transformer cooling oil, Nuclear frameworks cooling, Solar water heating, Nanofluids in boring, Refrigeration (domestic refrigerator, chillers), Defense, Space, High-power lasers, microwave tubes, Biomedical applications, Drilling, Lubrications, Thermal storage and Drag reductions.

The cooling system was first experimented and initiated by Tzeng (2005) and Nor (2015). This Experimental investigation of nanofluid used as a cooling system was testified in a car engine that the nanofluid is used as a base fluid produced by dispersing a similar size under $100 \mathrm{~nm}$ of metallic or non-metallic nanoparticles or nanofibers in a base fluid. His finding witnesses the presence of nanoparticles as in the base liquids contributing better stream of blending and higher thermal conductivity contrasted with unadulterated liquid. The performance of internal combustion engine gets improved 5to10\% by Senthilraja (2010) using Nanoparticle dispersed in engine coolant.

Ettefaghi et al. (2013) technical exploration describes that MWCNT-engine oil Maximum improvement of thermal conductivity of the nanofluids is $12.7 \%$ with 0.5 vol. \% of MWCNT nanoparticles at $20^{\circ} \mathrm{C}$.the intensive technical findings of Teng and Yu (2013a) and Ashutosh (2016) focuses that $0.4 \%$ vol. concentration enhances the heat transformation $49.6 \%$ while mixing MWCNT-EG/W. maximum efficiency factor is $14.1 \%$ at the low concentration of MWCNT nanoparticle.

It is often referred to as a "heat engine" because an internal combustion engine produces power by being fuel within the cylinder, whatsoever the environment is polluted because of the exhaust gas about $25 \%$ of the heat is converted to useful power. What happens to the remaining 75 percent? $30-35$ percent of the heat produced in the combustion chambers by the burning fuel is dissipated by the 
cooling system along with the lubrication and fuel systems. 40-45 percent of the heat produced passes out with the exhaust gases.

Interestingly Iijima (1991) discovered that Nanofluids have extraordinary possibilities to enhancement heavy duty, however increase of cooling rates gives engine's efficiency progression and also helps to reduce the engine weight and also to use the engine commodiously in the industrial space. It's seems to be a widel thermal management system in the competitive technical promotion. By means of this seame complexity (or) pattern the truck engines can be innovatively manufactured it leads to environmental safe and easy to handle. There are many opportunities in futuristic technical works by modifying the heavy duty motors to the light duty motors with the seame cooling technology along the software technologies. It's reduces the technical risk and nurture their skill.

Then again, he tried that it was profitable to design the more insignificant cooling system with humbler and lighter radiators and viably, along these lines, productive the predominant and high mileage of auto and truck gained ground. He found that Ethylene glycol-based nanofluids have pulled in much thought the application as motor coolant by Chougule (2014), Peyghambarzadeh (2011a) and Peyghambarzadeh (2011b) on account of the low-weight operation differentiated and a $50 / 50$ mix of ethylene glycol and water, which is the inside and out used auto coolant. He like manner found nanofluid has a high breaking point, and it can be used to construct the customary coolant working temperature and after that reject more warmth through the present coolant system Chavan (2014). Another disclosure was auto motor coolant $\left(\mathrm{Al}_{2} \mathrm{O}_{3}\right.$ nanofluid) using a standard auto motor coolant (HP KOOLGARD) as the base fluid Raja (2015) and concentrated the warm conductivity and consistency of the coolant. The arranged nanofluid, containing only $3.5 \%$ volume part of $\mathrm{Al}_{2} \mathrm{O}_{3}$ nanoparticles, demonstrated a truly higher thermal conductivity than the base fluid, and a most outrageous change of $10.41 \%$ was seen at room temperature. Tzeng et al. (2005) associated nanofluids to the cooling of modified transmissions. The adequately the trial organize was the transmission of a four-wheel drive vehicle. The used nanofluids were set up by diffusing $\mathrm{CuO}$ and $\mathrm{Al}_{2} \mathrm{O}_{3}$ nanoparticles into motor transmission oil. The results showed that $\mathrm{CuO}$ nanofluids conveyed the lower transmission temperatures both at high and low rotating speeds. From the warm execution point of view, the use of nanofluid in the transmission has a sensible favored stance.

The specialists of Argonne National Laboratory have evaluated the utilization of nanofluids for transportation. They found that the utilization of high-thermal conductive nanofluids in radiators can prompt a lessening in the frontal territory of the radiator up to $10 \%$. He found that the fuel sparing is up to $5 \%$ because of the decrease in aerodynamic drag. The outcome was it opens the entryway for new aerodynamic car plans that lessen discharges by bringing down drag. The use of nanofluids likewise added to a diminishment of erosion and wear, decreasing parasitic misfortunes, the operation of parts, for example, pumps and compressors, and in this manner prompting over $6 \%$ fuel reserve funds. Honestly, nanofluids not simply redesign the viability and money related execution of auto motor moreover will remarkably affect the structural framework of Automotives. For example, the engine radiator cooled by a nanofluid will be smaller and lighter.

It can be set somewhere else in the vehicle, taking into account the overhaul of a significantly more aerodynamic case. He tested by diminishing the size and changing the area of the radiator, a lessening in weight and wind resistance could empower more noteworthy fuel proficiency and hence bring down fumes. Experimental research on the convective heat exchange execution of nanofluids has been distributed with different blends of base liquids and suspensions by Lee (1999) and Tun (2013). The suspended nanomaterials amazingly expanded the constrained convective heat exchange execution of the base liquid. At a similar Reynolds number, the heat exchange of the nanofluid observed to be expanded with the molecule volume division. Sandesh (2014a) have done reviews on convective heat exchange upgrade of CNT-water nanofluid inside a vehicle radiator. They found that both nano coolants display a gigantic change in Nusselt number contrasted with typical water. It was seen that coolant with lower $\mathrm{pH}$ displays better execution contrasted with coolant with $\mathrm{pH}$ over 7.

The specialists Sandesh (2014b) in another paper concentrated the constrained convective heat exchange execution of two distinctive nanofluids Al2O3-water and CNT-water in a car radiator. The coolant flow rate is differed in the scope of 2-5 l/min. it bringing about heat exchange execution of CNT-water nanofluid was observed to be superior to anything $\mathrm{Al}_{2} \mathrm{O}_{3}$-water nano coolant. The revelation of convective heat by Teng and $\mathrm{Yu}$ (2013b) concentrated the convective heat exchange qualities of ethylene glycol water blend scattered with CNTs in an air cooled radiator. The most extreme upgraded proportion of heat trade under is observed to be $12.8 \%$ with a coolant flow rate of 8.5 LPM of MWCNTs is great contrasted with the SWNTs as the agglomerate size for a similar base nanofluid is significantly littler for MWNTs than for SWCNTs. Srinivasan (2017) studied and analysed about the missile with grid fins and the effect on flow drag using ANSYS. Godwin (2017) and Lakshmanan (2017) investigated about the optimum parameters for obtaining the best performance using alternate fuels of IC engines working under the current cooling system using Nanofluids. Venkatesh et al. (2016) studied the flow of heat and fluid in solar air heater using Computational Fluid Dynamics (CFD). The predicted temperature results were observed within a deviation of $\pm 10.64 \%$. 


\section{MATERIALS AND METHODS}

\subsection{Details of MWCNT Nanostructures}

Table 1 Description of MWCNT

\begin{tabular}{|c|c|}
\hline Property & Values \\
\hline $\begin{array}{c}\text { External } \\
\text { diameter }\end{array}$ & $50-80 \mathrm{~nm}$ \\
\hline $\begin{array}{c}\text { Internal } \\
\text { diameter }\end{array}$ & $5-15 \mathrm{~nm}$ \\
\hline True density & $2.1 \mathrm{~g} / \mathrm{cm}^{3}$ \\
\hline Bulk density & $0.18 \mathrm{~g} / \mathrm{cm}^{3}$ \\
\hline Length & $10-20 \mu \mathrm{m}$ \\
\hline Supplier & $\begin{array}{r}\text { Nanostructured \& Amorphous } \\
\text { Materials, Inc. Houston, } \\
\text { TEXAS, and USA. }\end{array}$ \\
\hline
\end{tabular}

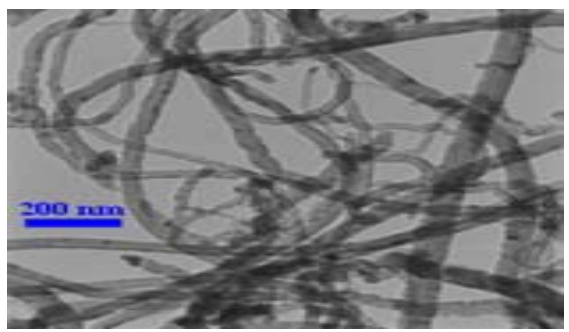

Fig. 1. SEM micrograph of MWCNT

\subsection{Preparation of MWCNT/Water Nanofluid}

The readiness of Nanofluids is the principle walk to the exploratory examinations of Nanofluids. The two fundamental systems to get ready Nanofluids are one stage technique and two-advance strategy by Godson (2010). The one-advance technique in the meantime makes and diffuses the nanoparticles directly into a base fluid. This methodology ensures stable dissipating and no agglomeration. In the twoarrange, framework nanoparticles are conveyed by one of the physical or compound blend strategies and keep on scattering them into a base fluid. In this examination, nanofluids were set up by using Multiwalled Carbon Nano Tube (MWCNT) with Distilled water, as base fluids at the volume centralization of $0.1,0.3$ and $0.5 \%$ and with including Sodium dodecyl butane sulfonate (SDBS) balancing out administrator by Hwang (2007). The two-step technique was used to prepare above nanofluids. In this audit required a measure of base fluid was first filled a 1-liter glass bottle and mixed with MWCNT of $0.1,0.3$ and $0.5 \%$ vol. obsession and the suspensions were scattered using an attractive stirrer done by Hiemenz (1986).The homogeneous arrangements were acquired after attractive blending as appeared in Fig.2.

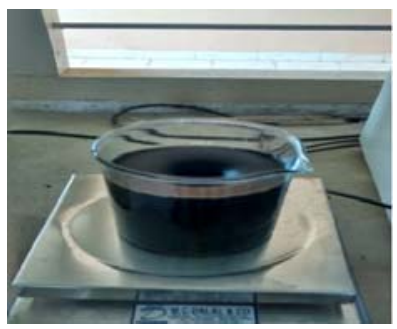

Fig. 2. Magnetic stirrer
The Magnetic stirrer uses a rotating attractive field which mixes the attractive pellet submerged in a fluid thusly empowering it to turn quickly which in this manner engaging the notwithstanding disseminating of the particles and ultrasonic vibrator (Toshiba, India) delivering ultrasonic beat of $40 \mathrm{~W}$ at $36 \pm 3 \mathrm{kHz}$ moreover ensures diffusing of particles in the fluid.

Sonication is a technique in which sound waves are used to disrupt particles in an arrangement. Such unsettling influences can be used to mix arrangement, speed the breaking down of a solid into a liquid (like sugar into water), and oust separated gas from liquids by Assael (2005). To get a uniform disseminating and stable suspension which chooses the last properties of nanofluids, the nanofluids are kept under the ultrasonic shower (Fig.3) reliably for 3 hours with kept up $40^{\circ} \mathrm{C}$.

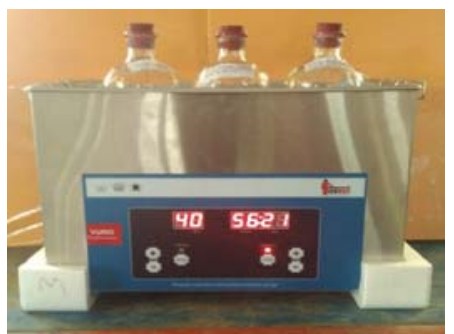

Fig. 3. Ultrasonic bath

\subsection{Stability inspection of MWCNT/Water} Nanofluid

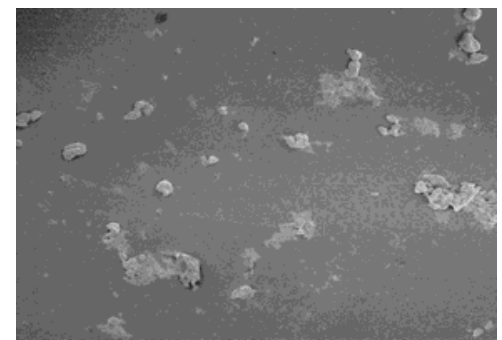

Fig. 4. FESEM image of MWCNT in $0.0 .1 \%$ of volumetric concentration

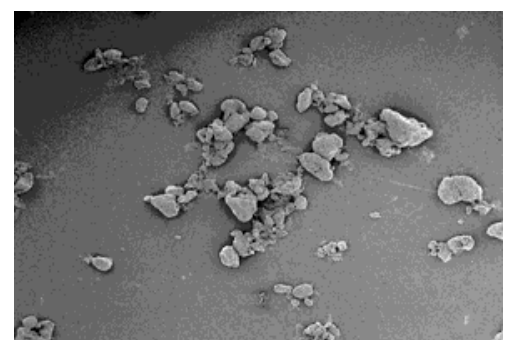

Fig. 5. FESEM image of MWCNT in $0.3 \%$ of volumetric Concentration

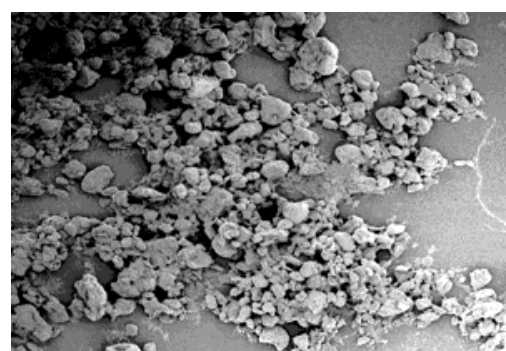

Fig. 6. FESEM image of MWCNT in $0.5 \%$ of volumetric Concentration 
Above FESEM structure $0.1 \%$ volume concentration is very poor Particle are visible but $0.3 \%$ is moderately presented MWCNT and also uniformly distributed, where $0.5 \%$ is more particle are concentrated so that, this fluid is very poor viscosity, from this image $0.3 \%$ is the better stability of coolant.

\section{EXPERIMENTAL SETUP}

Fig.7 demonstrates the schematic diagram of the exploratory setup.The set up is four stroke diesel engines with alternator generator. This is consists of storage vessels with a valve to control the flow on the tube, magnet pump, flow meter, engine, car radiator, connected with a plastic hose. The engine cooling water inlet (Tin) and hot water outlet (Tout) is with connected car radiator. Hot water Inlet and cold water outlet of the radiator temperatures measure with help of thermocouple. The output of radiator cooling water is stored in the reservoir with help of magnet pump. The dimensions of from the test section are: the engine four strokes (Kirloskar) 5 HP, connected Tube inner diameter(di) $12.7 \mathrm{~mm}$, outer diameter(do)13mm, magnet pump is (330 LPH), with Maruthi 800 car radiator.

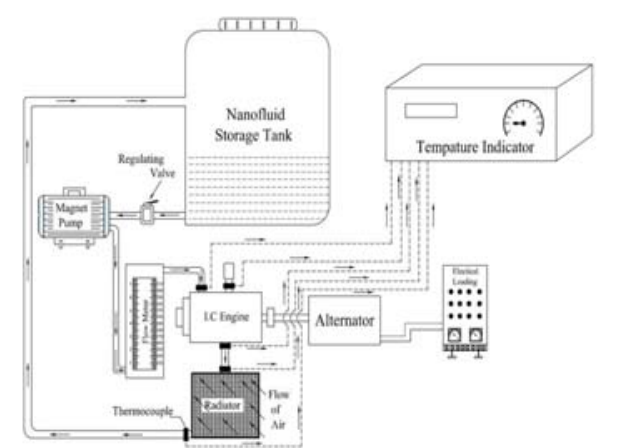

Fig. 7. Schematic diagram of the exploratory setup

\subsection{Experimental procedure}

Water is circulated to test the leakage, the function of thermocouples, U-tube manometer and thermostat checked. Cold water is allowed to cooling water jacket and the pump is switched on continuous water Circulation. Know engine is started with the maximum speed of 1500rpm no load conditions .the the corresponding temperature is recorded with help of thermocouples. Similarly, various particle volume concentrations of nanofluids such as $0.1,0.3$ and $0.5 \%$ are circulated through the engine water jacket. The flow rate of water and nanofluids is kept constant (330 LPH) and flow rate on the tube side. The temperatures are measured during before attaining the steady state. After half an hour constant temperature is maintained $39^{\circ} \mathrm{C}$ after that varying different load conditions like No load, 500W, 1000W, 1500W, 2000w The exhaust temperature of MWCNT measured with thermocouples.

\section{RESUltS AND DiscuSSIONS}

\subsection{Experimental Indicated Power}

In this experimental work, when compared to water, the indicated Power is for $300 \mathrm{LPH}$ is increases in $0.3 \%$ concentration of nano fluid. And also when compared to $0.3 \%$ concentration of nano fluid, the indicated power is decreases for other concentrations of nanofluids as shown in figure 8.

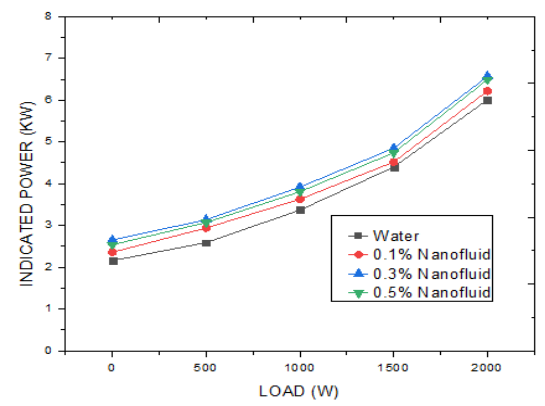

Fig. 8. Effect of load on indicated power

\subsection{Experimental Brake Power}

In this experimental work, when compared to water, the Brake Power is for $300 \mathrm{LPH}$ is almost same in 0.1 and $0.5 \%$ concentration of nano fluid. But $0.3 \%$ concentration of nano fluid is slightly increases when compared to other concentrations of nano fluid as well as water is shown in Figure 9.

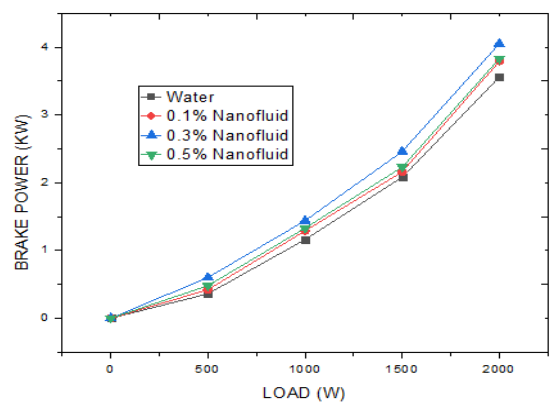

Fig. 9. Effect of load on brake power

\subsection{Experimental Brake Thermal Efficiency}

When compared to water, the brake thermal efficiency is gradually increases for 0.3 and $0.5 \%$ concentration of nano fluids. But brake thermal efficiency of $0.1 \%$ concentration of nano fluid is almost similar to water as shown in figure 10 .

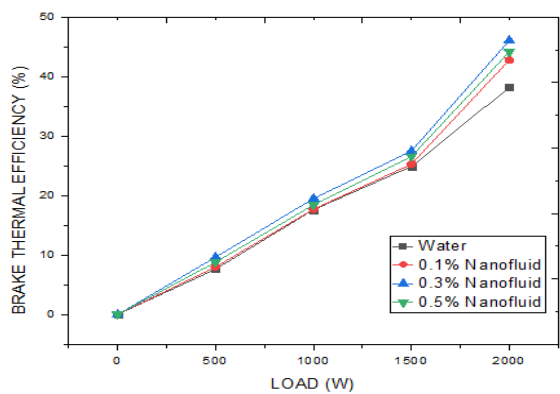

Fig. 10. Effect of load on brake thermal efficiency

\subsection{Experimental Mechanical Efficiency}

Figure 11 illustrates the effect of load on mechanical efficiency. When compared to water, the mechanical efficiency is increases for different concentrations of nano fluids. 


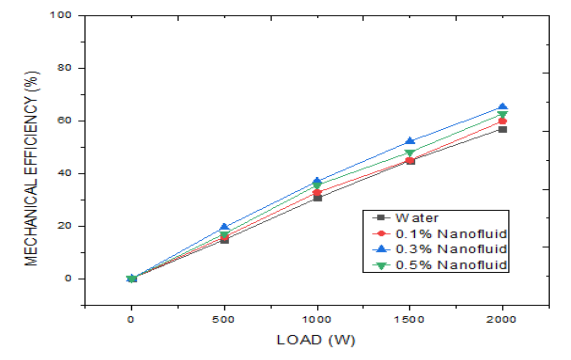

Fig. 11. Effect of load on mechanical efficiency

\subsection{Experimental Specific Fuel Consumption}

Figure 12 shows the effect of loads on specific fuel consumption. SFC for $300 \mathrm{LPH}$ is decreases in $0.1 \%$ of MWCNT/Water. When compared to $0.1 \%$ concentrations of nano fluid, other concentrations of nano fluid is decreases.

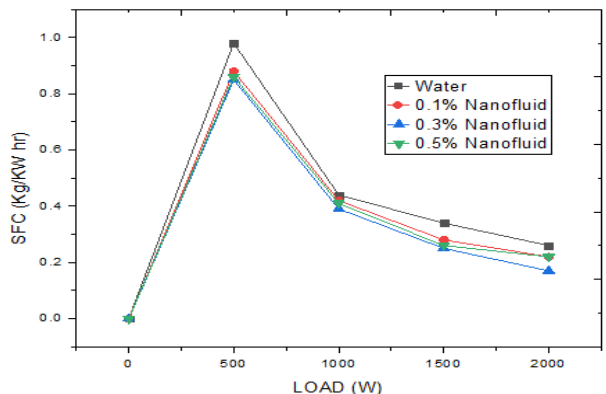

Fig. 12. Effect of load on specific fuel consumption

\subsection{Experimental Total Fuel Consumption}

Figure 13 illustrates the effect of loads on total fuel consumption. TFC for $300 \mathrm{LPH}$ is increases in $0.5 \%$ MWCNT/Water, but 0.3 and $0.1 \%$ concentration of nano fluid is linearly decreases with respect to load.

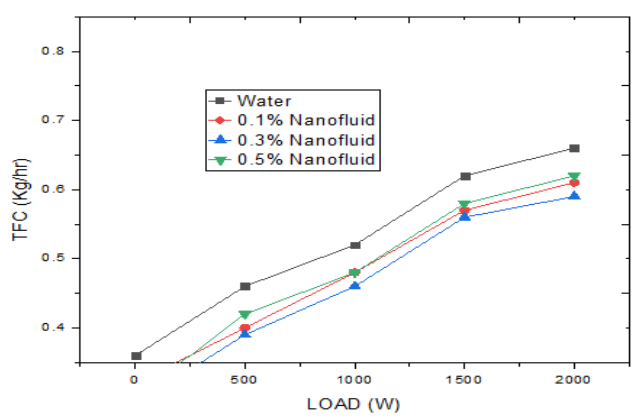

Fig. 13. Effect of load on total fuel consumption

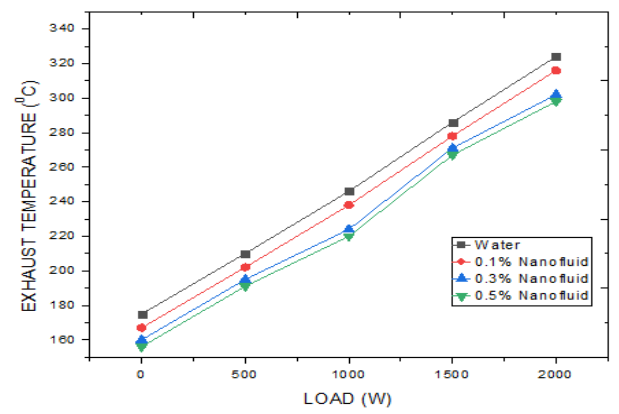

Fig. 14. Effect of load on exhaust temperature

\subsection{Experimental Exhaust Gas Temperature}

Figure 14 illustrates the variations of loads with exhaust temperature, the exhaust temperatures decrease by $2-15 \%, 6-20 \%$ \& $2-16 \%$ against 0.1 , 0.3 and $0.5 \%$ volume concentration of nano fluid respectively This enhancement is due to the higher heat transfer coefficient of nanofluids than water.

\section{CONCLUSION}

In this paper, Experimental analysis of four stroke diesel engine handling carbon nanotube based nanofluids at $0.1,0.3$ and $0.5 \%$ of particle volume concentration with 300LPH flow rate was tested. The I.C Engine Performance of nanofluids has been compared with water. Following observations were made from the investigations.

(i). The $0.3 \%$ MWCNT/water nanofluid found to have good stability up to 30 days from the date of preparation.

(ii). The mechanical efficiency gradually increases by 5 to $7 \%, 13$ to $24 \%$, and 7 to $14 \%$ against $0.1 \%, 0.3 \%$ and $0.5 \%$ vol. concentration of nanofluids respectively.

(iii). The Break thermal efficiency significantly increases at $0.5-11 \%, 9-21 \%$ and $4-14 \%$ against $0.1 \%, \quad 0.3 \%$ and $0.5 \%$ vol. concentration of nanofluids while comparing with water.

(iv). The TFC reduces at $7-11 \%, 9-19 \%$ and 6$16 \%$ against $0.1 \%$, $0.3 \%$ and $0.5 \%$ nanofluids while comparing with water. The SFC reduces at $4-17 \%, 11-34 \%$ and $6-24 \%$ against $0.1 \%, 0.3 \%$ and $0.5 \%$ nanofluids while comparing with water. It is studied that the $0.3 \%$ nanofluid gives remarkable reduction in SFC and TFC.

(v). The exhaust temperature of the engine decreases by $1-2 \%, 5-10 \%$ \& $3-5 \%$ against $0.1,0.3$ and $0.5 \%$ volume concentration of nanofluid respectively at $300 \mathrm{LPH}$ and at 0W,500W, 1000W, 1500W, and 2000W. It is clear that the $0.3 \%$ nanofluid significantly reduces exhaust temperature.

(vi). Further work is needed at various coolant flow rate like $270,330 \mathrm{LPH}$, at $0.1, \quad 0.3$, and $0.5 \%$ volume concentration.

\section{REFERENCES}

Ashutosh Pimpalkar, U., U. Darshana Pimpalkar, S. Rekha Rathod, P. Suraj Bhivagade (2016) Advance water cooling system in two-wheeler bike engine: case study, International Organization of engineering Research \& Development Journal (IOERD) Volume 1 Issue 2. 
Assael, M. J., I. N. Mataxa, J. Arvanitidis, D. Christophilos, C. Lioutas (2005) Thermal conductivity enhancement in aqueous suspensions of carbon multi-walled and double-walled nanotubes in the presence of two different dispersants", Int. J. Thermo phys. 26, 647-664.

Azwadi Che Sidik, N., M. Noor AfiqWitri Mohd Yazid , R. Mamat (2015) A review on the application of nanofluids in vehicle engine cooling system, International Communications in Heat and Mass Transfer 68 ,85-90.

Chavan, D. and A. T. Pise (2014) Performance investigation of an automotive car radiator operated with nanofluid as a coolant, $J$. Thermal Sci. Eng. Appl. 6, 021010.

Chougule, S. S. and S. K. Sahu (2014) Comparative study of cooling performance of automobile radiator using $\mathrm{Al}_{2} \mathrm{O}_{3}$-water and carbon nanotube-water nanofluid, J. Nanotechnol. Eng. Med. 5, 011001.

Elcock, D. (2007) Potential impacts of nanotechnology on energy transmission applications and needs. Environmental Science Division, Argonne National Laboratory.

Ettefaghi, E. O. L., H. Ahmadi, A. Rashidi, A. Nouralishahi, S.S. Mohtasebi, (2013) Preparation and thermal properties of oil-based nanofluid from multi-walled carbon nanotubes and engine oil as nano-lubricant, Int. Comm. Heat Mass Transfer 46, 142-147.

Godson, L., D. M. Lal \& S. Wong wises (2010) Measurement of thermo physical properties of metallic nanofluids for high temperature applications, Nanoscale and micro scale thermo physical engineering, 14(3), 152-173.

Godwin Antony, A., S. Dinesh, K. Rajaguru, V. Vijayan (2017) Analysis and Optimization of Performance Parameters in Computerized I.C. Engine Using Diesel Blended with Linseed Oil and Leishmaan's Solution, Mechanics and Mechanical Engineering 21(2) 193-205.

Hiemenz, P. C. and M. Dekker (1986) Principles of colloid and surface chemistry, Second ed., Dekker, New York.

Hindawi (03.11.09) http:// downloads hindawi.com/journals/ame/si/htn.pdf

Hwang, Y., J. K. Lee, C. H. Lee, Y. M. Jung, S. I. Cheong, C. G. Lee, B. C. Ku, and S. P. Jang (2007) Stability and thermal conductivity characteristics of nanofluids, Thermo chim. Acta 455(1-2) 70-74.

Iijima S. (1991) Nature, 354:56.
Lakshmanan, P., P. Kaliyappan, M. Ranjithkumar, K. Aravinth, D. Vakkachan, C. Moorthy and S. Kumar (2017) An Experimental Investigation to Study the Performance and Emission Characteristics of Chicken Fat Oil Fuelled DI Diesel Engine, Journal of Applied Fluid Mechanics 10, Special Issue, 85-91

Lee, S., S. U. S. Choi, S. Li, J. A. Eastman (1999) Measuring Thermal Conductivity of Fluids Containing Oxide Nanoparticles, Journal of Heat Transfer 121(2), 280 - 289,

Peyghambarzadeh, S. M., S. H. Hashemabadi, M. S. Jamnani, S. M. Hoseini (2011) Improving the cooling performance of automobile radiator with Al2O3/water nanofluid, Appl. Therm. Eng. 31, 1833-1838.

Peyghambarzadeh, S. M., S. H. Hashemabadi, S. M. Hoseini, M. Seifi Jamnani, (2011) Experimental study of heat transfer enhancement using water/ethylene glycol based nanofluids as a new coolant for car radiators, Int. Commun. Heat Mass Transfer 38, 1283-1290.

Raja, M., R. Vijayan, S. Suresh, R. Vivekananthan (2013) Effect of heat transfer enhancement and NOx emission using Al2O3/water nanofluid as coolant in CI engine, Ind. J. Eng. Mater. Sci. 20, 443-449.

Sandesh C. and S. K. Sahu (2014) Comparative Study of Cooling Performance of Automobile Radiator Using $\mathrm{Al}_{2} \mathrm{O}_{3}$-Water and Carbon Nanotube-Water Nanofluid, Journal of Nanotechnology in Engineering and Medicine 5(1), 011001-1-011001-5.

Sandesh, S. C. and S. K. Sahu (2014) Thermal Performance of Automobile Radiator Using Carbon Nanotube-Water NanofluidExperimental Study, Journal of thermal science and engineering applications 6(4), 041009 .

Senthilraja, S., M. Karthikeyan and R. Gangadevi (2010) Nanofluid Applications in Future Automobiles: Comprehensive Review of Existing Data, NANO-MICRO LETTERS 2(4) 306-310.

Srinivasan, R., V. Vijayan and K. Sridhar (2017) Computational Fluid Dynamic Analysis of Missile with Grid Fins Journal of Applied Fluid Mechanics 10, Special Issue, 33-39.

SUS. Choi. In: DA. Singer, HP. Wang, editors (1995). Development and application of nonNewtonian flows, vol. FED 231. New York: ASME; p. 99-105.

Teng, T. P. and C. C. Yu (2013) Heat dissipation performance of MWCNTs nano-coolant for 
M. Muruganandam and P. C. Mukesh Kumar /JAFM, Vol. 11, Special Issue, pp. 15-21, 2018.

vehicle, Exp. Thermal Fluid Sci. 49, 22-30.

Tzeng, S. C., C. W. Lin, K. D. Huang (2005) Heat transfer enhancement of nanofluids in rotary blade coupling of four-wheel-drive vehicles, Acta Mech. 179, 11-23.
Venkatesh, R. and V. Vijayan (2016) Performance Evaluation of Multipurpose Solar Heating System, Mechanics and Mechanical Engineering, 20 (4), 359-370. 